\title{
Mass drug administration of ivermectin in south-eastern Senegal reduces the survivorship of wild-caught, blood fed malaria vectors
}

\author{
Massamba Sylla ${ }^{1 * \dagger}$, Kevin C Kobylinski ${ }^{1{ }^{*}}$, Meg Gray ${ }^{1}$, Phillip L Chapman², Moussa D Sarr ${ }^{3}$, Jason L Rasgon ${ }^{4,5}$,
} Brian D Foy ${ }^{1 *+}$

\begin{abstract}
Background: In south-eastern Senegal, malaria and onchocerciasis are co-endemic. Onchocerciasis in this region has been controlled by once or twice yearly mass drug administration (MDA) with ivermectin (IVM) for over fifteen years. Since laboratory-raised Anopheles gambiae s.s. are susceptible to ivermectin at concentrations found in human blood post-ingestion of IVM, it is plausible that a similar effect could be quantified in the field, and that IVM might have benefits as a malaria control tool.
\end{abstract}

Methods: In 2008 and 2009, wild-caught blood fed An. gambiae s.l. mosquitoes were collected from huts of three pairs of Senegalese villages before and after IVM MDAs. Mosquitoes were held in an insectary to assess their survival rate, subsequently identified to species, and their blood meals were identified. Differences in mosquito survival were statistically analysed using a Glimmix model. Lastly, changes in the daily probability of mosquito survivorship surrounding IVM MDAs were calculated, and these data were inserted into a previously developed, mosquito age-structured model of malaria transmission.

Results: Anopheles gambiae s.s. $(P<0.0001)$ and Anopheles arabiensis $(P=0.0191)$ from the treated villages had significantly reduced survival compared to those from control villages. Furthermore, An gambiae s.s. caught 1-6 days after MDA in treated villages had significantly reduced survival compared to control village collections $(P=0.0003)$, as well as those caught pre-MDA $(P<0.0001)$ and $>7$ days post-MDA $(P<0.0001)$. The daily probability of mosquito survival dropped $>10 \%$ for the six days following MDA. The mosquito age-structured model of malaria transmission demonstrated that a single IVM MDA would reduce malaria transmission $\left(R_{0}\right)$ below baseline for at least eleven days, and that repeated IVM MDAs would result in a sustained reduction in malaria $R_{0}$.

Conclusions: Ivermectin MDA significantly reduced the survivorship of An. gambiae s.s. for six days past the date of the MDA, which is sufficient to temporarily reduce malaria transmission. Repeated IVM MDAs could be a novel and integrative malaria control tool in areas with seasonal transmission, and which would have simultaneous impacts on neglected tropical diseases in the same villages.

\section{Background}

Every year, an estimated 500 million people are afflicted with malaria worldwide, killing more than one million people, most of whom are children in sub-Saharan

\footnotetext{
* Correspondence: massamba.sylla@colostate.edu; kobylinskikevin@yahoo. com; brian.foy@colostate.edu

† Contributed equally

${ }^{1}$ Arthropod-borne and Infectious Diseases Laboratory, Department of Microbiology, Immunology \& Pathology, Colorado State University, Fort Collins, Colorado, USA

Full list of author information is available at the end of the article
}

Africa [1,2]. Current control measures for preventing malaria transmission in Africa focus on the use of longlasting insecticide-treated nets (LLITNs) treated with pyrethroids and indoor residual spraying (IRS) with organochlorines and pyrethroids. Both of these control methods have proven effective as a means for reducing Plasmodium transmission by endophagic malaria vectors but are potentially threatened by vector resistance to the currently used insecticides [3]. The development of novel methods to reduce Plasmodium transmission that

\section{() Biomed Central}


can integrate with and enhance current malaria control measures, as well as other health priorities, is critical.

In 1987, ivermectin (IVM) was registered for human use for the control of onchocerciasis [4] and later for lymphatic filariasis [5]. Its primary effects are against microfilariae in the human body, which are the transmissible parasite stages of these diseases. Ivermectin has been used extensively since the mid-1990's in mass drug administration (MDA) campaigns across Africa by the African Programme for Onchocerciasis Control (APOC) [6] and the Global Program to Eliminate Lymphatic Filariasis (GPELF) [5]. Annually, more than 80 million people across the tropics are treated with IVM by MDA [7].

Previous in vitro and animal studies demonstrated that IVM can reduce the survivorship of multiple mosquito species after ingesting the drug in blood [8-11]. Wilson [12] reviewed these and other studies and suggested that the avermectins might impart their strongest impact on disease transmission by reducing vector longevity thereby reducing vectorial capacity. Concentrations of IVM found in human venous plasma after standard IVM MDA $(150 \mu \mathrm{g} / \mathrm{kg})$ reduced the survivorship and reblood feeding frequency of laboratory-reared Anopheles gambiae s.s., which are the two most critical variables in models of vectorial capacity [13]. Two studies have directly blood fed laboratory-reared Anopheles spp. mosquitoes on humans who have ingested IVM. Foley et al [14] reported reduced Anopheles farauti survivorship when mosquitoes fed on one person who ingested $250 \mu \mathrm{g} / \mathrm{kg}$ of IVM. Chaccour et al [15] found that An. gambiae s.s. blood fed on humans one day after they had ingested $200 \mu \mathrm{g} / \mathrm{kg}$ of IVM had significantly reduced survivorship, but the effect was not apparent fourteen days post-ingestion. To date, the only field based study on the effects of IVM against wild mosquitoes was performed in Papua New Guinea and focused on lymphatic filariasis control. Bockarie et al [16] demonstrated that MDA with IVM $(400 \mu \mathrm{g} / \mathrm{kg})$ in combination with diethylcarbamazine citrate $(6 \mathrm{mg} / \mathrm{kg})$ in one village reduced the survivorship of wild Anopheles punctulatus up to four days after MDA. In another village, MDA with IVM $(400 \mu \mathrm{g} / \mathrm{kg})$ alone reduced the survivorship of wild An. punctulatus captured the day after MDA [16].

The goal of this study was to determine if IVM MDA of humans in Senegal for onchocerciasis control could simultaneously reduce the survivorship of wild African malaria vectors, and if so, for how long this effect would occur, and to model this effect on malaria transmission. Villages in south-eastern Senegal have been treated once or twice yearly with IVM MDA $(150 \mu \mathrm{g} / \mathrm{kg})$ for onchocerciasis eradication for over fifteen years [17]. This same region has hyperendemic malaria transmission
$[18,19]$ and has an abundant and diverse Anopheles malaria vector fauna [20]. In 2008 and 2009, blood-fed Anopheles spp. were captured from inside peoples' huts before and after IVM MDA in three replicate pairs of villages in south-eastern Senegal. Survivorship of the mosquitoes was assessed by holding them in a field insectary for five days. Mosquito survivorship data were then incorporated into a modified previously-developed model [21] to evaluate the potential of IVM to reduce malaria transmission. The results demonstrate that IVM MDA reduces the survivorship of wild An. gambiae s.s. and that this reduction in survivorship should be sufficient to reduce malaria transmission.

\section{Methods}

\section{Study site}

The study was conducted in the villages of Boundacoundi, Damboucoye, Nathia, Ibel and Ndebou, all in the Sudano-Guinean zone of rural south-eastern Senegal. The five villages are located along a $15 \mathrm{~km}$ stretch of road heading west out of Kedougou. Most of the people in this area are subsistence farmers. They live in extended family compounds with 2-10 sleeping huts, and cultivate maize, sorghum and groundnuts between these compounds and in separate fields outside the village. Cattle, sheep, goats, dogs, and chickens are the primary domesticated animals in the villages. In 2008, two villages were sampled, Ibel and Ndebou. Ibel was treated by MDA with $150 \mu \mathrm{g} / \mathrm{kg}$ of IVM $\left(\right.$ Mectizan $^{\mathrm{Tm}}$, Merck \& Co., Inc) on August 8, 2008, while Ndebou was not treated and served as the paired control village. In 2009, two pairs of villages were sampled. Ndebou and Boundacoundi were the first pair of villages sampled and MDA occurred on August 6, 2009 in Ndebou, with Boundacoundi serving as the control. Damboucoye and Nathia were the second pair of villages sampled and MDA occurred on October 11, 2009 in Damboucoye, with Nathia serving as the control. MDA was coordinated by APOC in Senegal and the Senegalese Ministry of Health, and performed through community-directed treatment by the local nurses. Permission to conduct mosquito sampling surrounding these MDAs was granted first by the Senegalese Ministry of Health and then by the residents of each village. The study was also reviewed by the Colorado State University Institutional Review Board prior to being conducted.

\section{Mosquito collections}

Indoor resting, wild, blood fed Anopheles mosquitoes were collected in the morning from huts people had slept in the previous night using backpack aspirators (John W. Hock, Gainesville, FL, USA). After capture, Anopheles mosquitoes were transferred by mouth aspirators from backpack aspirator cups to $473 \mathrm{ml}$ cardboard 
containers screened with organdy. The containers were labelled and designated by village, date collected, and the specific hut from which mosquitoes were collected. Containers were placed into a large basket and two moist towels were placed over the top of the basket to keep the mosquitoes humid and cool. Immediately following morning aspirations, the mosquitoes were transported back to the insectary in Bandafassi (2008) or Kedougou (2009) and maintained on shelves. Insectaries were designated rooms of houses and had screened and slatted windows so that they naturally fluctuated with the ambient temperature and humidity. Temperature and humidity within the insectary ranged from $\left(27-30^{\circ}\right.$ C) and (66 - 86\%). Any dead, non-blood fed, or nonAnopheles mosquitoes were removed from the containers upon placement in the insectary. The containers had a moistened sponge and raisins placed on top to serve as water and sugar sources for the mosquitoes. Survivorship was checked daily at 12:00 pm and dead mosquitoes were removed from the containers. The containers were then randomly placed back onto the shelves. All mosquitoes that survived for five days were frozen and counted as alive on day five post-capture. In 2009, both the treated and the control village were sampled on the same day by two separate field teams. In 2008, only one village was sampled on each day (Additional file 1).

\section{Mosquito processing}

Mosquitoes were identified morphologically to species $[22,23]$ in the field insectary immediately following their death. The abdomens were separated from the thoraxes of all Anopheles spp. and placed into two separate $1.5 \mathrm{ml}$ microfuge tubes containing the silica gel desiccant T.H.E. (EMD Chemicals, NJ, USA). The tubes were labelled with the village, date of aspiration and hut location, and all relevant information was recorded on matching log sheets. Processed mosquitoes were shipped back to Colorado State University for further molecular analysis. DNA was extracted with the Qiagen DNeasy kit (Qiagen Sciences, Maryland, USA) and a Qiacube robot (Qiagen Sciences, Maryland, USA). Multiplex polymerase chain reaction was used to molecularly identify members of the An. gambiae s.l. complex [24]. A subset of twelve or fewer An. gambiae s.l. from each collection day that died within one day of capture and contained undigested blood at the time of processing had their blood meals analysed by the multiplex polymerase chain reaction to determine the source of blood [25].

\section{Survivorship model and statistics}

A generalized linear mixed (Glimmix) model was used to assess the effects of IVM MDA on mosquito survivorship. Mosquito survivorship results for each village at each sampling date were classified by treatment (whether or not they originated from a treatment or control village), replicate (the three pairs of villages sampled over the two field seasons), and phase. The three phases are groups of sampling dates from each village before MDA (phase 1), one to six days after MDA (phase 2), and seven days or more after MDA (phase 3). The one to six day grouping immediately after MDA was chosen based on the differential survivorship curves generated from the three replicates (Figure 1). Treatment and phase were treated as fixed effects. Replicates were treated as random effects with sample date nested within replicate and phase. The model was fit by the SAS Glimmix procedure using maximum likelihood estimation with three Gaussian quadrature points (SAS Institute, Cary, NC, USA). The percent survivorship of mosquitoes was tested for interaction of treatment by phase, and if significant, then post-tests were performed to determine which treatment by phase groups significantly differed from the others. The efficacy of IVM to reduce mosquito survivorship would be reflected by a significant drop in the treated village survivorship at the phase 2 group compared to control and pre-treatment groups.

Modelling the change in the basic reproductive number of malaria due to ivermectin mass drug administrations A linear calculation of the daily probability of survivorship was determined from the five-day survivorship values of $A n$. gambiae s.l. captured before and after MDA from all three replicates. These daily probability of survivorship estimates were then inserted into an

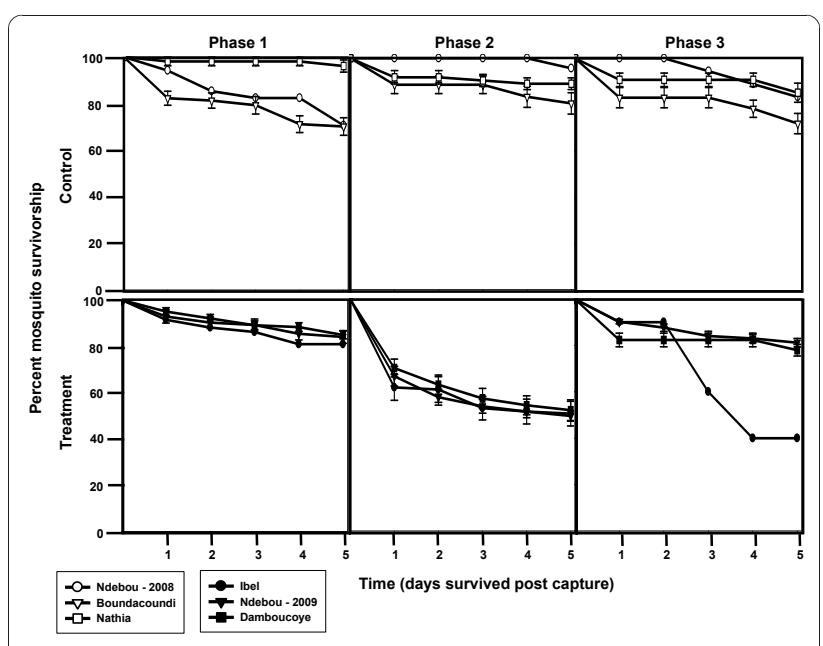

Figure 1 Percent survivorship of aspirated An. gambiae s.s. grouped by treatment and phase. Percent survivorship of all aspirated An. gambiae s.s. $(N=1265)$ held five days post-capture from all three replicates. Standard error bars represent the percent survivorship variation of all mosquitoes from each village grouped within each treatment and phase. 
age-structured model of mosquito population dynamics from Billingsley et al [21] with several minor modifications. The proportion of treated humans was not held constant, but rather varied temporally based on MDA coverage. It was assumed that once treated with drug, humans remained mosquitocidal to feeding Anopheles for six days. Output of this model was used as input for an age-structured model [21] showing the relative change in the basic reproductive number of malaria during IVM treatment. A relative $R_{0}<1$ indicates a decrease in transmission, while relative $R_{0}>1$ indicates an increase in transmission and relative $R_{0}=1$ indicates no change.

Immature mosquito lifestages were assumed to have a daily survival rate of 0.9 . Based on the data estimated from field-collected mosquitoes, it was assumed that mosquitoes that imbibed blood from an untreated human had a daily survival rate of 0.96 , while mosquitoes that fed on a treated human had a daily survival rate of 0.86 for 3 days post-feeding. To be conservative, it was assumed that after feeding on a treated human, mosquitoes experienced a decrease in their daily survival rate for three days post-feeding, after which they recovered to untreated levels. An extrinsic incubation period of fourteen days was used for the model. Age-specific fecundity was not affected by IVM as was previously stated [21].

\section{Results}

\section{Mosquito survivorship analysis}

Figure 1 depicts the percent survivorship of An. gambiae s.s. from all three replicates grouped by treatment and phase. There is an observable reduction in An. gambiae s.s. survivorship after IVM MDA (phase 2) in the treated villages that lasts for six days. The survivorship of $A$. gambiae s.s. in Ibel during phase 3 is low (Figure 1), but this line only represents ten mosquitoes caught from one collection (Additional file 1). A total of 1,265 An. gambiae s.s. from three replicates were captured and held for survivorship analysis. The model of estimated mosquito survivorship for An. gambiae s.s. identified a treatment by phase interaction, indicating that the difference between treated and control survivorship depends on phase $(\mathrm{F}$-value $=18.27, \mathrm{P}<0.0001)$ (Figure 2). In follow-up comparisons, treatment at phase 2 significantly differed from control at phase 2 ( $\mathrm{t}$-value $=$ 4.01, $\mathrm{P}=0.0003$ ), and it also significantly differed from both treatment at phase 1 , pre-MDA ( $\mathrm{t}$-value $=8.31, \mathrm{P}$ $<0.0001)$ and treatment at phase 3, seven days and after IVM MDA ( $\mathrm{t}$-value $=-4.61, \mathrm{P}<0.0001$ ). The conclusion of this analysis is that IVM MDA significantly reduced the survivorship of An. gambiae s.s. for six days past the date of the MDA.

Adequate numbers for survivorship analysis of An. arabiensis were only caught during the third replicate

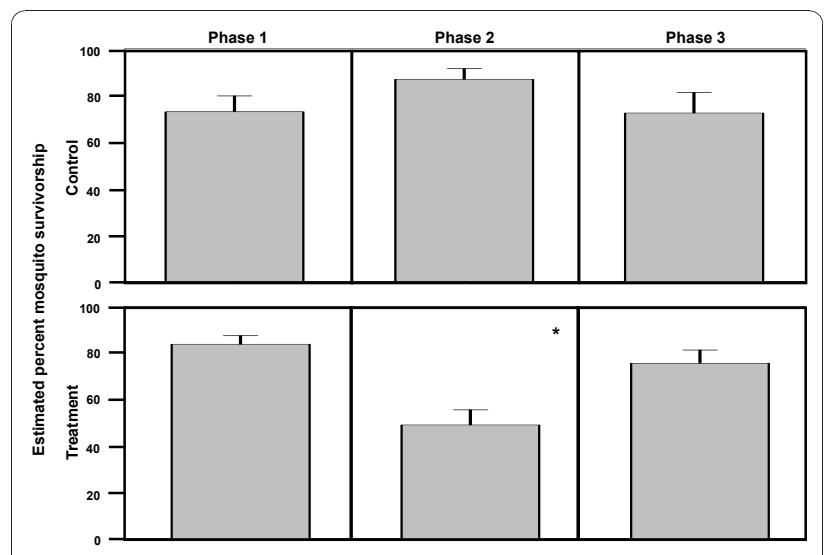

Figure 2 Glimmix model estimated percent survivorship of An. gambiae s.s. grouped by treatment and phase. Glimmix model estimated percent survivorship of all An. gambiae s.s. $(\mathrm{N}=1265)$ held five days post-capture from all three replicates. * Treatment by phase was significant ( $F$-value $=18.27, \mathrm{P}<0.0001$ ). Treatment at phase 2 significantly differed from control at phase 2 ( $t$-value $=4.01$, $\mathrm{P}=0.0003)$, treatment at phase $1(\mathrm{t}-\mathrm{value}=8.31, \mathrm{P}<0.0001)$, and treatment at phase 3 (t-value $=-4.61, P<0.0001)$.

(Damboucoye and Nathia, $\mathrm{n}=153$ ). There appears to be a reduction in survivorship of An. arabiensis following IVM MDA (Figure 3), but treatment by phase comparisons were not significantly different from each other $(\mathrm{F}$-value $=0.66, \mathrm{P}=0.5332)$. However, treatment alone was significant $(\mathrm{F}$-value $=7.01, \mathrm{P}=0.0191)$, therefore the overall survivorship of An. arabiensis was lower in the treated village compared to the control village (Figure 4).

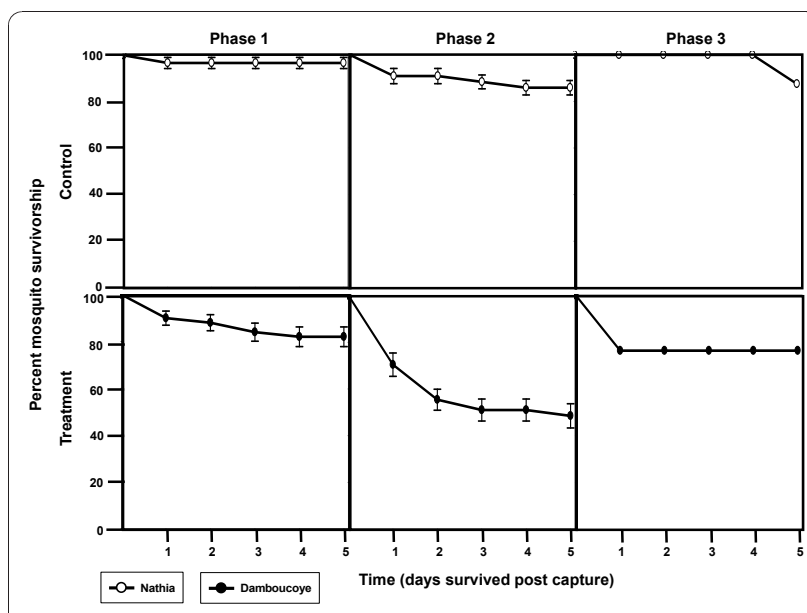

Figure 3 Percent survivorship of aspirated An. arabiensis grouped by treatment and phase. Percent survivorship of all aspirated An. arabiensis $(N=153)$ held five days post-capture from Nathia and Damboucoye. Standard error bars represent the percent survivorship variation of all mosquitoes from each village grouped within each treatment and phase. 


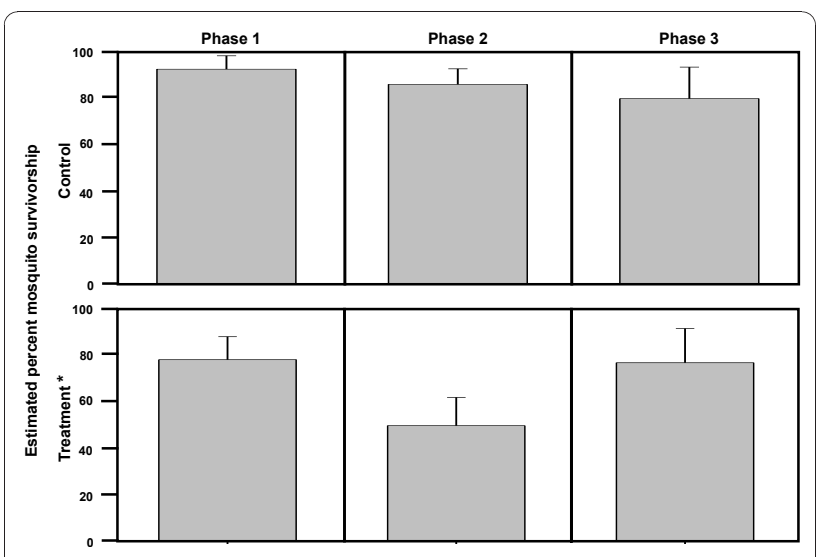

Figure 4 Glimmix model estimated percent survivorship of An. arabiensis grouped by treatment and phase. Glimmix model estimated percent survivorship of all An. arabiensis $(N=153)$ held five days post-capture from Nathia and Damboucoye. *Treatment was significant ( $F$-value $=7.01, P=0.0191)$.

\section{Blood meal analysis}

Almost all, 97.8\% (136/139), of An. gambiae s.s. blood meals that were analysed were from humans. Based on this information it was assumed that almost all of the An. gambiae s.s. held for the study had fed on humans. However, only $75 \%(24 / 32)$ of analysed An. arabiensis blood meals were from humans (Figure 5 ).

\section{Modelling the effect of ivermectin treatment on malaria transmission}

Simulations indicate that MDA with IVM can significantly reduce $R_{0}$ for a short period of time after drug administration (Figure 6A). Using the previously stated assumptions and an ideal situation of $100 \%$ coverage, a synchronized MDA of IVM results in an approximately 90\% reduction in $\mathrm{R}_{0}$ immediately following MDA (Figure 6A). After effective drug concentrations are cleared from the blood of the human population, $\mathrm{R}_{0}$ rebounds to pre-treatment levels or slightly higher if no

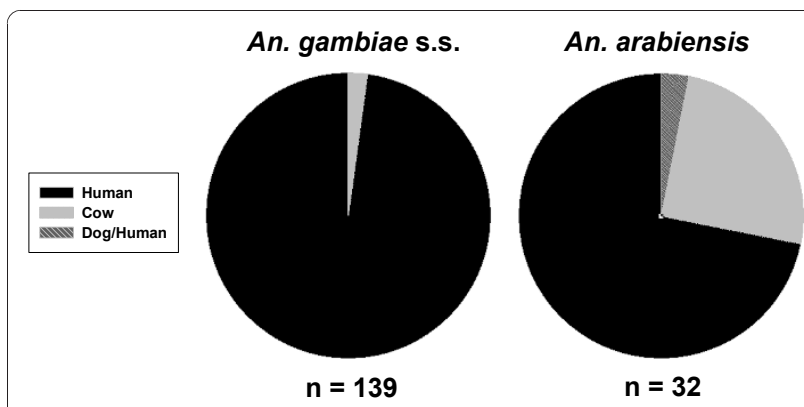

Figure 5 Percent composition of blood meal sources of aspirated An. gambiae s.I. The percent blood meal sources of a subset of An. gambiae s.s. $(n=139)$ and An. arabiensis $(n=32)$ aspirated from all five villages in 2008 and 2009. further MDAs are performed. To keep relative $R_{0}$ levels at significantly lower levels, drug treatment must be administered repeatedly. Less frequent treatments allow for periods of control alternated with periods of no control (Figure 6A).

Due to the fluctuating nature of the control dynamics, where $R_{0}$ is changing on a daily basis, it is more informative to compare average relative $R_{0}$ between different treatment intervals. This can be easily calculated by summing the area under the curve for both pre and post-treatment scenarios. Under the ideal conditions of $100 \%$ coverage with treatment every week, mean $R_{0}$ can be reduced by $80 \%$. Lower levels of coverage or less frequent MDAs reduce the efficacy of this strategy, but in all cases MDA resulted in some level of control (Figure 6B).

\section{Discussion}

Previously published laboratory based evidence showed that colonized An. gambiae s.s. is susceptible to IVM at concentrations relevant to human pharmacokinetics after a typical MDA [13], and that colonized An. gambiae s.s. fed on IVM-treated humans one day post-treatment had reduced survivorship [15]. The current study now demonstrates that routine MDA of IVM to people significantly reduces the survivorship of wild An. gambiae s.s. for up to six days post MDA. This six day lethal effect is longer than the two days observed from Kobylinski et al. [13], and this effect occurs despite incomplete MDA coverage in treated villages. Three field replicates were performed over space and time in different villages to make this study a rigorous assessment of the effects of IVM MDA on An. gambiae s.l.

There were no significant differences in An. arabiensis treatment by phase survivorship $(\mathrm{F}$-value $=0.66, \mathrm{P}=$ 0.5332 ) but this was almost certainly due to sampling, in that adequate numbers $(n=153)$ for survivorship analysis were only captured in the third replicate MDA. The third replicate MDA was performed in October 2009, toward the end of the rainy season when An. arabiensis is more prevalent [20]. There was a $38 \%$ reduction in mosquito survivorship from phase 2 treatment collections compared to phase 2 control collections (Figure 4). The fact that treatment alone was significant $(\mathrm{F}$-value $=7.01, \mathrm{P}=$ 0.0191), means that the overall survivorship of $A n$. arabiensis was lower in the treated village compared to the control village (Figure 4). Furthermore, only 75\% (24/32) of $A n$. arabiensis blood meals were from humans (Figure 5), which reduces the probability that mosquitoes held for survivorship analysis may have ingested an IVMcontaining blood meal. Fritz et al [26] reported that colonized $A n$. gambiae s.s. and colonized An. arabiensis have almost identical susceptibility to IVM. When these data are considered together, it is reasonable to assume that 


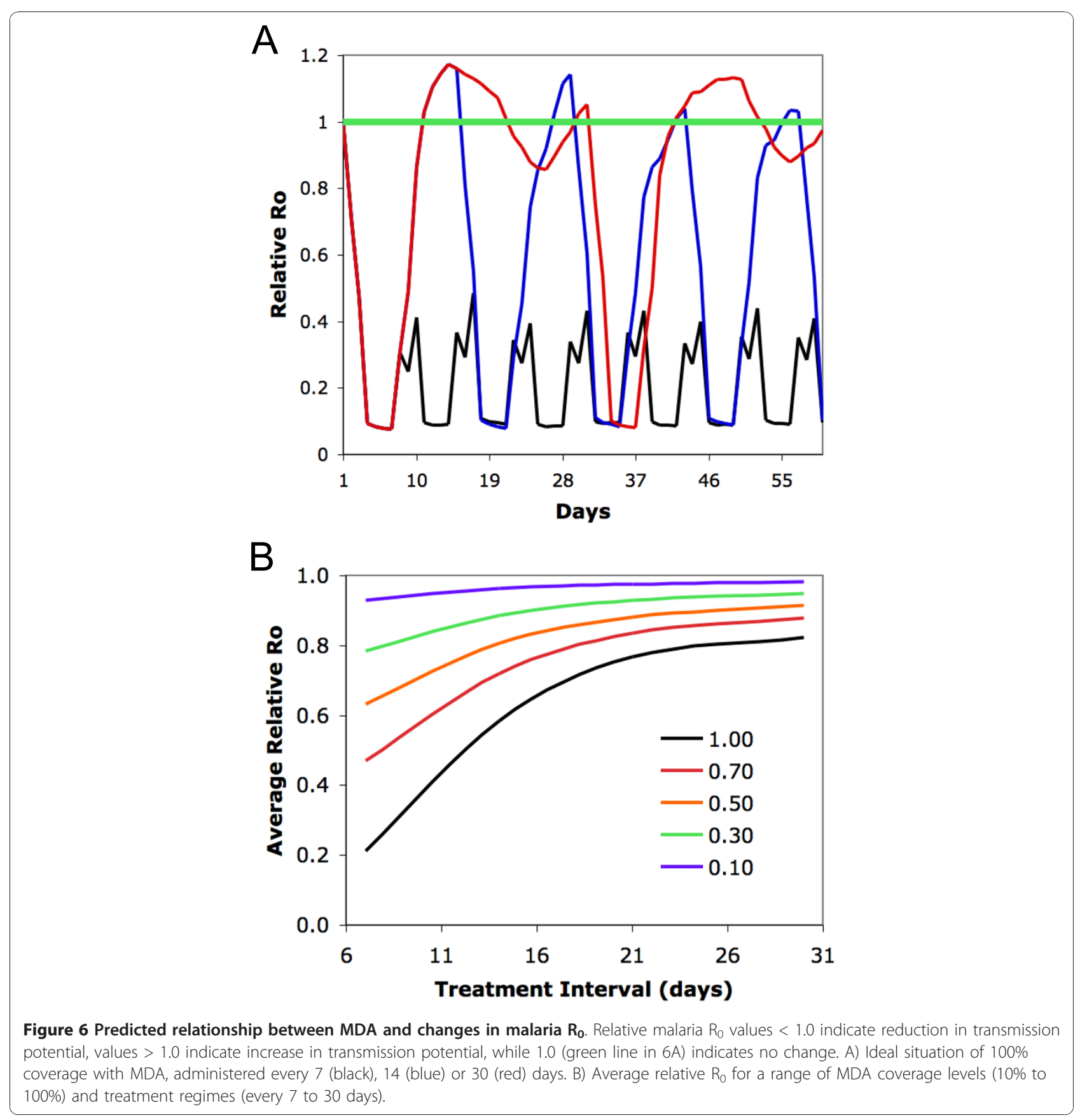

upon further replication wild An. arabiensis will be shown to be as susceptible to IVM MDA as wild $A n$. gambiae s.s.

Based on clinical records, $84.2 \%$ (203/241) of people in Damboucoye and $82.1 \%(311 / 379)$ of people in Ndebou were treated with IVM during these two MDAs. Pregnant women and children under $90 \mathrm{~cm}$ did not receive the drug, following the manufacturer guidelines. Mosquitoes that were held for survivorship analysis for five days had completely digested their blood meals, which made it impossible to detect IVM from individual mosquitoes. Yet it is impressive that mosquito survival was still significantly reduced despite not knowing whether any one mosquito fed on a treated person. Incomplete coverage may actually be beneficial to the overall concept of repeated IVM MDAs for malaria control in that it may provide a refugia of untreated human hosts for mosquitoes to feed on which could reduce the likelihood of IVM resistance development in the mosquito population. 
Of people accounted, $78.2 \%(903 / 1,155)$ utilized ITNs across the four villages surveyed in 2009. Even with high ITN coverage, human blood fed An. gambiae s.s. and $A n$. arabiensis were frequently collected from the inside of huts, demonstrating that ITNs have limitations in preventing Anopheles from feeding on people in huts. Exophagic and exophilic malaria vectors also comprise an important part of the malaria transmission cycle in this study area; Anopheles funestus group mosquitoes are almost twice as likely to blood feed outdoors than indoors [20], and Anopheles nili tend to be exophilic or immediately exit huts after biting [20,27]. ITNs may reduce malaria transmission by exophagic vectors [28-30], but their primary efficacy is against endophagic vectors. It has also been shown that ITNs may shift vector host seeking times to earlier in the evening when people will not be sleeping under an ITN [31]. IRS will only affect the survivorship of endophilic vectors that contact the sprayed surfaces, and it is believed that the exophilic portion of the An. gambiae s.l. population led to the failure of IRS to eliminate malaria transmission during the Garki project [32]. Furthermore, a number of malaria vectors will naturally feed at dusk and dawn, when humans are less likely to be indoors and protected by an ITN or by IRS. Ivermectin MDA may be one of the few methods that can directly target these exophagic, exophilic, and crepuscular-feeding malaria vectors, and should integrate well with the employment of existing in-home control methods like ITNs and IRS.

Ivermectin has a different mode of action from the insecticide classes currently used for ITNs and IRS (i.e., carbamates, pyrethroids, and organochlorines) [3], in that it agonizes the glutamate-gated chloride anion channels found in invertebrate postsynaptic neurons and neuromuscular junctions [33,34]. This action hyperpolarizes the neurons and muscle fibers, leading to flaccid paralysis and insect death [35-37]. Once or twice yearly IVM MDA has been occurring in this region for over fifteen years [17], so the fact that a reduction in survivorship of An. gambiae s.s. was still detectable is a promising sign that resistance by Anopheles spp. may be slow to develop against this drug. Furthermore, the novel mode of action of ivermectin compared the currently used insecticides for malaria control should potentially minimize issues of cross-resistance where IVM MDA may be used in combination with IRS and ITNs.

Anopheles gambiae s.s. often requires two blood meals to complete its initial gonotrophic cycle $[38,39]$ and thereafter will often take multiple blood meals per gonotrophic cycle [40-42] and feeds almost exclusively on humans (Figure 5) [20]. These blood feeding characteristics, coupled to the fact that the extrinsic incubation period for Plasmodium spp. is 9-14 days, means that most malaria transmission by An. gambiae s.s. will occur only after Plasmodium parasite-harbouring mosquitoes have taken multiple non-sporozoite transmitting blood meals from humans [21,43]. If human population clusters were simultaneously treated with IVM MDA, then most adult $A n$. gambiae s.s. in the MDA area would imbibe a concentration of IVM that would reduce their survivorship. The predicted effect has the potential to temporarily shift the An. gambiae s.s. population age structure, which would reduce the reservoir of adult sporozoite-transmitting An. gambiae s.s. in the MDA area. The low sporozoite rate in the resulting mosquito population would temporarily reduce the basic reproductive number $\left(R_{0}\right)$ of malaria below the base number for approximately eleven days post IVM MDA. Current IVM MDAs for onchocerciasis control in Africa are performed only once or twice per year, and do not always coincide with local malaria transmission seasons. Such current applications would not be expected to lower malaria transmission long enough to see any noticeable reductions of parasite prevalence, intensity or disease in people. Indeed, malaria is hyperendemic in APOCcontrol areas of south-eastern Senegal despite IVM MDAs for more than 15 years. However, if IVM MDA is administered repeatedly, $R_{0}$ can be reduced for an extended period of time.

This model, like all models, makes assumptions that may not be realistic in nature, such as homogeneous mosquito biting, no spatial structure, and the lack of density-dependent effects. However, the model results are conservative, since it only incorporates the direct IVM-related mortality effect observed in the field. Kobylinski et al [13] demonstrated in the lab that multiple sub-lethal IVM containing blood meals compounds mosquito mortality, but the model assumes complete recovery of surviving mosquitoes three days after ingesting an IVM-containing blood meal. Kobylinski et al [13] also demonstrated that the re-blood feeding frequency and blood digestion of An. gambiae s.s. are delayed after imbibing relevant IVM concentrations. Finally, Fritz et al [26] and personal observations have witnessed mosquito knockdown effects immediately after drug ingestion. All of these negative sub-lethal effects would probably lead to a further reduction in An. gambiae s.s. survivorship in the field, due to desiccation, predation, or insufficient nutrition, beyond that of outright mortality induced by IVM. Thus, it may be that the agestructured model is an underestimate of the true effect of IVM MDA on malaria transmission.

The age-structured model predicts that strategically administered, repeated IVM MDAs would achieve sustained reductions in malaria transmission. Such repeated MDAs may only be logistically feasible for areas with seasonal malaria transmission, such as the Sahel, or in 
areas experiencing malaria epidemics. An expanded IVM MDA regimen fits well with the idea of combating polyparasitism in some of these same communities $[44,45]$. Malaria and soil-transmitted helminths (STHs Ascaris lumbricoides, Trichuris trichiura, Strongyloides stercoralis, and hookworms) are co-endemic across much of sub-Saharan Africa [46-50]. The annual/biannual IVM MDAs for onchocerciasis control are not generally sufficient for controlling STHs because of relatively rapid re-infections due to their transmission dynamics [51-55]. Repeated IVM MDAs are likely to result in reductions of the prevalence and intensities of STHs in individuals receiving the drug [52-59], and would increase the personal incentive to participate in such MDAs. The combination of malaria and soiltransmitted helminth infections can exacerbate anaemia, resulting in worsened child development and more adverse pregnancy outcomes than these diseases cause on their own [60-64]. Therefore, the combined effects of IVM MDA on multiple parasites could potentially reduce anaemia in the human population which would lead to an overall improvement in human health beyond what would be expected from malaria control alone.

Future field work will need to be conducted to determine if repeated IVM MDAs can quantifiably reduce malaria transmission and if the model created here is an over or underestimate of what would occur in the field. Important to this future work is determining whether a logistically feasible IVM MDA interval can be devised that would reduce malaria transmission below a critical threshold and not foster IVM resistance in either Anopheles vectors or human nematode parasites.

\section{Conclusions}

This study demonstrates that IVM MDA reduces the survivorship of wild-caught An. gambiae s.s. for up to six days post MDA and the modelled field data shows that repeated IVM MDAs should result in a sustained reduction of malaria transmission. Ivermectin MDA would be both a novel insecticide class and delivery method for reducing vector survivorship. It should also affect exophagic, exophilic, and crepuscular-feeding malaria vectors not normally targeted by malaria control measures. Repeated IVM MDAs should concomitantly reduce $\mathrm{STH}$ prevalence and intensities, which would further benefit human health beyond that of malaria control alone.

\section{Additional material}

Additional file 1: Number of mosquitoes captured by aspiration by mosquito species, village, year, phase, and date. The number of mosquitoes caught each aspiration collection by date and grouped by phase. *Coll - number of aspiration collections performed per phase.
**Trtmt - whether or not a village was treated by IVM MDA. **\#ct number of each mosquito species caught that aspiration collection.

\section{Acknowledgements}

We would like to thank Dr. Doudou Sene, head of the medical district of the Kedougou region, Mactar Mansaly, Infirmier d'Etat a Bandafassi, Rigobert Keita and Filly Keita for their collaboration. We also thank the people of Ndebou, Ibel, Boundacoundi, Nathia, and Damboucoye for their hospitality and collaboration. This work was supported by grant Al079528, and by contract N01-Al-25489 from the U.S. National Institutes of Allergy and Infectious Diseases, by the Bill and Melinda Gates Foundation's Grand Challenges Explorations program and by Colorado State University CVMBS Research Council \#1686174.

\section{Author details}

${ }^{1}$ Arthropod-borne and Infectious Diseases Laboratory, Department of Microbiology, Immunology \& Pathology, Colorado State University, Fort Collins, Colorado, USA. ${ }^{2}$ Department of Statistics, Colorado State University, Fort Collins, Colorado, USA. ${ }^{3}$ Ministère de la Santé et de la Prévention Médicale, Dakar, Senegal. ${ }^{4}$ The W. Harry Feinstone Department of Molecular Microbiology and Immunology, Bloomberg School of Public Health, Johns Hopkins University, Baltimore, Maryland 21205, USA. ${ }^{5}$ The Johns Hopkins Malaria Research Institute, Bloomberg School of Public Health, Johns Hopkins University, Baltimore, Maryland, USA.

\section{Authors' contributions}

MS, KCK, and BDF designed research; MS, KCK, MG and BDF performed research; BDF contributed reagents; MS, KCK, MDS and BDF coordinated field studies, MS, KCK, PLC, JLR and BDF analysed data/developed models; MS, KCK, JLR and BDF wrote the paper; MS, KCK, MG, PLC, JLR and BDF edited the paper. All authors read and approved the final manuscript.

\section{Competing interests}

The authors declare that they have no competing interests.

Received: 4 October 2010 Accepted: 20 December 2010

Published: 20 December 2010

\section{References}

1. Hay SI, Okiro EA, Gething PW, Patil AP, Tatem AJ, Guerra CA, Snow RW: Estimating the global clinical burden of Plasmodium falciparum malaria in 2007. PLOS Med 2010, 7:e1000290.

2. Snow RW, Craig M, Deichmann U, Marsh K: Estimating mortality, morbidity and disability due to malaria among Africa's non-pregnant population. Bull World Health Organ 1999, 77:624-640.

3. Hemingway J, Ranson $\mathrm{H}$ : Chemical control of vectors and mechanisms of resistance. In Biology of Disease Vectors.. 2 edition. Edited by: Marquardt WC. San Diego: Elsevier Academic Press; 2005:627-647.

4. Thylefors B: The Mectizan Donation Program (MDP). Ann Trop Med Parasitol 2008, 102:39-44.

5. Ottesen EA, Hooper PJ, Bradley M, Biswas G: The global programme to eliminate lymphatic filariasis: health impact after 8 years. PLOS Negl Trop Dis 2008, 2:e317.

6. Amazigo U: The African Programme for Onchocerciasis Control (APOC). Ann Trop Med Parasitol 2008, 102:19-22.

7. Mectizan Donation Program. [http://www.mectizan.org/]

8. Pampiglioni S, Majori G, Petrangeli G, Romi R: Avermectins, MK-933 and MK-936, for mosquito control. Trans R Soc Trop Med Hyg 1985, 79:797-799.

9. Tesh RB, Guzman H: Mortality and infertility in adult mosquitoes after the ingestion of blood containing ivermectin. Am J Trop Med Hyg 1990, 43:229-233.

10. Jones JW, Meisch MV, Meek CL, Biven WS: Lethal effects of ivermectin on Anopheles quadrimaculatus. J Am Mosq Control Assoc 1992, 8:278-280.

11. Gardner K, Meisch MV, Meek CL, Biven WS: Effects of ivermectin in canine blood on Anopheles quadrimaculatus, Aedes albopictus and Culex salinarius. J Am Mosa Control Assoc 1993, 9:400-402.

12. Wilson ML: Avermectins in arthropod vector management - prospects and pitfalls. Parasitol Today 1993, 9:83-87. 
13. Kobylinski KC, Deus KM, Butters MP, Hongyu T, Gray M, da Silva IM, Sylla M, Foy BD: The effect of oral anthelmintics on the survivorship and refeeding frequency of anthropophilic mosquito disease vectors. Acta Trop 2010, 116:119-126.

14. Foley DH, Bryan JH, Lawrence GW: The potential of ivermectin to control the malaria vector Anopheles farauti. Trans R Soc Trop Med Hyg 2000, 94:625-628.

15. Chaccour C, Lines J, Whitty CJM: Effect of ivermectin on Anopheles gambiae mosquitoes fed on humans: the potential of oral insecticides in malaria control. J Infect Dis 2010, 202:113-116.

16. Bockarie MJ, Hii JL, Alexander ND, Bockarie F, Dagoro H, Kazura JW Alpers MP: Mass treatment with ivermectin for filariasis control in Papua New Guinea: impact on mosquito survival. Med Vet Entomol 1999, 13:120-123.

17. Diawara L, Traore MO, Badji A, Bissan Y, Doumbia K, Goita SF, Konate L, Mounkoro K, Sarr MD, Seck AF, Toe L, Touree S, Remme JHF: Feasibility of onchocerciasis elimination with ivermectin treatment in endemic foci in Africa: first evidence from studies in Mali and Senegal. PloS Negl Trop Dis 2009, 3:e497.

18. Kleinschmidt I, Omumbo J, Briet O, van de Giesen N, Sogoba N, Mensah NK, Windmeijer P, Moussa M, Teuscher T: An empirical malaria distribution map for West Africa. Trop Med Int Health 2001, 6:779-786.

19. Gemperli A, Sogoba N, Fondjo E, Mabaso M, Bagayoko M, Briet OJT, Anderegg D, Liebe J, Smith T, Vounatsou P: Mapping malaria transmission in West and Central Africa. Trop Med Int Health 2006, 11:1032-1046.

20. Dia I, Diop T, Rakotoarivony I, Kengne P, Fontenille D: Bionomics of Anopheles gambiae Giles, An. arabiensis Patton, An. funestus Giles and An. nili (Theobald) (Diptera: Culicidae) and transmission of Plasmodium falciparum in a Sudano-Guinean zone (Ngari, Senegal). J Med Entomol 2003, 40:279-283.

21. Billingsley PF, Foy B, Rasgon JL: Mosquitocidal vaccines: a neglected addition to malaria and dengue control strategies. Trends Parasitol 2008, 24:396-400.

22. Diagne N, Fontenille D, Konate L, Faye O, Lamizana MT, Legros F, Molez JF, Trape JF: The Anopheles of Senegal - an annotated and illustrated check list. Bull Soc Pathol Exot 1994, 87:267-277.

23. Hervy J, Le Goff G, Geoffroy B, Herve J, Manga L, Brunhes J: Logiciel d'identification et d'enseignement. Les Anophèles de la région afrotropicale. Série Didactiques ORSTOM, OCEAC, CD-ROM 1998.

24. Scott JA, Brogdon WG, Collins FH: Identification of single specimens of the Anopheles gambiae complex by the polymerase chain reaction. Am J Trop Med Hyg 1993, 49:520-529.

25. Kent RJ, Norris DE: Identification of mammalian blood meals in mosquitoes by a multiplexed polymerase chain reaction targeting cytochrome b. Am J Trop Med Hyg 2005, 73:336-342.

26. Fritz ML, Siegert PY, Walker ED, Bayoh MN, Vulule JR, Miller JR: Toxicity of bloodmeals from ivermectin-treated cattle to Anopheles gambiae s.l. Ann Trop Med Parasitol 2009, 103:539-547.

27. Service MW: Behaviour of Anopheles nili Theobald in sprayed huts in northern Nigeria. J Trop Med Hyg 1964, 67:11-12.

28. Charlwood JD, Alcantara J, Pinto J, Sousa CA, Rompao H, Gil V, Rosario VE: Do bednets reduce malaria transmission by exophagic mosquitoes? Trans Roy Soc Trop Med Hyg 2005, 99:901-904.

29. Richards FO, Klein RE, Flores RZ, Weller S, Gatica M, Zeissig R, Sexton J: Permethrin-impregnated bed nets for malaria control in northern Guatemala - epidemiologic impact and community acceptance. Am J Trop Med Hyg 1993, 49:410-418.

30. Govella NJ, Okumu FO, Killeen GF: Insecticide-treated nets can reduce malaria transmission by mosquitoes which feed outdoors. Am J Trop Med Hyg 2010, 82:415-419.

31. Charlwood JD, Graves PM: The effect of permethrin-impregnated bednets on a population of Anopheles farauti in coastal Papua New Guinea. Med Vet Entomol 1987, 1:319-327.

32. Molineaux L, Gramiccia G: The Garki project: research on the epidemiology and control of malaria in the Sudan savanna of West Africa Geneva: World Health Organization; 1980.

33. Cully DF, Vassilatis DK, Liu KK, Paress PS, Vanderploeg LHT, Schaeffer JM, Arena JP: Cloning of an avermectin-sensitive glutamate-gated chloride channel from Caenorhabditis elegans. Nature 1994, 371:707-711.

34. Kane NS, Hirschberg B, Qian S, Hunt D, Thomas B, Brochu R, Ludmerer SW, Zheng Y, Smith M, Arena JP, Cohen CJ, Schmatz D, Warmke J, Cully DF:
Drug-resistant Drosophila indicate glutamate-gated chloride channels are targets for the antiparasitics nodulisporic acid and ivermectin. Proc Natl Acad Sci USA 2000, 97:13949-13954

35. Cully DF, Paress PS, Liu KK, Schaeffer JM, Arena JP: Identification of a Drosophila melanogaster glutamate-gated chloride channel sensitive to the antiparasitic agent avermectin. J Biol Chem 1996, 271:20187-20191.

36. Wolstenholme AJ, Rogers AT: Glutamate-gated chloride channels and the mode of action of the avermectin/milbemycin anthelmintics. Parasitol 2005, 131(Suppl):S85-95.

37. Bloomquist JR: Chloride channels as tools for developing selective insecticides. Arch Insect Biochem Physiol 2003, 54:145-156.

38. Gillies M: The pre-gravid phase of ovarian development in Anopheles funestus. Ann Trop Med Parasitol 1955, 49:320-325.

39. Charlwood JD, Pinto J, Sousa CA, Ferreira C, Petrarca V, Rosario VD: 'A mate or a meal' - Pre-gravid behaviour of female Anopheles gambiae from the islands of Sao Tome and Principe, West Africa. Malar J 2003, 2:9.

40. Beier JC: Frequent blood-feeding and restrictive sugar-feeding behaviour enhance the malaria vector potential of Anopheles gambiae s.l. and An. funestus (Diptera:Culicidae) in western Kenya. J Med Entomol 1996, 33:613-618.

41. Gillies M: The duration of the gonotrophic cycle in Anopheles gambiae and Anopheles funestus, with a note on the efficiency of catching. East Afr Med J 1953, 30:975-985

42. Briegel H, Horler E: Multiple blood meals as a reproductive strategy in Anopheles (Diptera, Culicidae). J Med Entomol 1993, 30:975-985.

43. Foy BD, Killeen GF, Magalhaes T, Beier JC: Immunological targeting of critical insect antigens. Am Entomol 2002, 48:150-163.

44. Hotez PJ, Molyneux DH, Fenwick A, Ottesen E, Ehrlich Sachs S, Sachs JD: Incorporating a rapid-impact package for neglected tropical diseases with programs for HIV/AIDS, tuberculosis, and malaria. PLoS Med 2006, 3: e102.

45. Sachs JD, Hotez PJ: Fighting tropical diseases. Science 2006, 311:1521.

46. Brooker S, Clements ACA, Hotez PJ, Hay SI, Tatem AJ, Bundy DAP, Snow RW: The co-distribution of Plasmodium falciparum and hookworm among African schoolchildren. Malar J 2006, 5:99.

47. Clements ACA, Deville MA, Ndayishimive O, Brooker S, Fenwick A: Spatial co-distribution of neglected tropical diseases in the East African Great Lakes region: revisiting the justification for integrated control. Trop Med Int Health 2010, 15:198-207.

48. Glinz D, N'Guessan NA, Utzinger J, N'Goran EK: High prevalence of Strongyloides stercoralis among school children in rural Cote d'Ivoire. J Parasitol 2010, 96:431-433.

49. Hay SI, Guerra CA, Gething PW, Patil AP, Tatem AJ, Noor AM, Kabaria CW, Manh BH, Elyazar IRF, Brooker S, Smith DL, Moyeed RA, Snow RW: A world malaria map Plasmodium falciparum endemicity in 2007. PLoS Med 2009, 6:e1000048.

50. Olsen A, van Lieshout $L$, Marti $H$, Polderman $T$, Polman $K$, Steinmann $P$, Stothard R, Thybo S, Verweij JJ, Magnussen P: Strongyloidiasis - the most neglected of the neglected tropical diseases? Trans Roy Soc Trop Med Hyg 2009, 103:967-972

51. Anderson RM, Medley GF: Community control of helminth infections of man by mass and selective chemotherapy. Parasitol 1985, 90:629-660.

52. Beach MJ, Streit TG, Addiss DG, Prospere R, Roberts JM, Lammie PJ: Assessment of combined ivermectin and albendazole for treatment of intestinal helminth and Wuchereria bancrofti infections in Haitian schoolchildren. Am J Trop Med Hyg 1999, 60:479-486.

53. Belizario $\mathrm{VY}$, Amarillo ME, de Leon WU, de los Reyes AE, Bugayong MG, Macatangay BJC: A comparison of the efficacy of single doses of albendazole, ivermectin, and diethylcarbamazine alone or in combinations against Ascaris and Trichuris spp. Bull World Health Organ 2003, 81:35-42.

54. Whitworth JAG, Morgan D, Maude GH, Downham MD, Taylor DW: A community trial of ivermectin for onchocerciasis in Sierra Leone adverse reactions after the 1 st five treatment rounds. Trans $R$ Soc Trop Med Hyg 1991, 85:501-505.

55. Gutman J, Emukah E, Okpala N, Okoro C, Obasi A, Miri ES, Richards FO: Effects of annual mass treatment with ivermectin for onchocerciasis on the prevalence of intestinal helminths. Am J Trop Med Hyg 2010, 83:534-541.

56. Geary TG, Woo K, McCarthy JS, Mackenzie CD, Horton J, Prichard RK, de Silva NR, Olliaro PL, Lazdins-Helds JK, Engels DA, Bundy DA: Unresolved 
issues in anthelmintic pharmacology for helminthiases of humans. Int $J$ Parasit 2010, 40:1-13.

57. Marti H, Haji HJ, Savioli L, Chwaya HM, Mgeni AF, Ameir JS, Hatz C: A comparative trial of a single-dose ivermectin versus three days of albendazole for treatment of Strongyloides stercoralis and other soiltransmitted helminth infections in children. Am J Trop Med Hyg 1996, 55:477-481.

58. Ranque S, Chippaux JP, Garcia A, Boussinesq M: Follow-up of Ascaris lumbricoides and Trichuris trichiura infections in children living in a community treated with ivermectin at 3-monthly intervals. Ann Trop Med Parasitol 2001, 95:389-393.

59. Wen $L Y$, Yan $X L$, Sun FH, Fang YY, Yang MJ, Lou L: A randomized, doubleblind, multicenter clinical trial on the efficacy of ivermectin against intestinal nematode infections in China. Acta Trop 2008, 106:190-194.

60. Brooker S, Hotez PJ, Bundy DAP: Hookworm-related anaemia among pregnant women: a systematic review. PloS Negl Trop Dis 2008, 2:e291.

61. Midzi N, Mtapuri-Zinyowera S, Mapingure MP, Sangweme D, Chirehwa MT, Brouwer KC, Mudzori J, Herema G, Mutapi F, Kumar N, Mduluza T: Consequences of polyparasitism on anaemia among primary school children in Zimbabwe. Acta Trop 2010, 115:103-111.

62. Mwangi TW, Bethony JM, Brooker S: Malaria and helminth interactions in humans: an epidemiological viewpoint. Ann Trop Med Parasitol 2006, 100:551-570

63. Yatich NJ, Yi J, Agbenyega T, Turpin A, Rayner JC, Stiles JK, Ellis WO, Funkhouser E, Ehiri JE, Williams JH, Jolly PE: Malaria and intestinal helminth co-infection among pregnant women in Ghana: prevalence and risk factors. Am J Trop Med Hyg 2009, 80:896-901.

64. Yatich NJ, Jolly PE, Funkhouser E, Agbenyega T, Rayner JC, Ehiri JE, Turpin A, Stiles JK, Ellis WO, Jiang Y, Williams JH: The effect of malaria and intestinal helminth coinfection on birth outcomes in Kumasi, Ghana. Am J Trop Med Hyg 2010, 82:28-34.

doi:10.1186/1475-2875-9-365

Cite this article as: Sylla et al:: Mass drug administration of ivermectin in south-eastern Senegal reduces the survivorship of wild-caught, blood fed malaria vectors. Malaria Journal 2010 9:365.

\section{Submit your next manuscript to BioMed Central and take full advantage of:}

- Convenient online submission

- Thorough peer review

- No space constraints or color figure charges

- Immediate publication on acceptance

- Inclusion in PubMed, CAS, Scopus and Google Scholar

- Research which is freely available for redistribution

Submit your manuscript at www.biomedcentral.com/submit 